\section{PENGARUH KARAKTERISTIK DEMOGRAFI, DIMENSI KETERLIBATAN KONSUMEN, DAN PENGENALAN KEBUTUHAN TERHADAP KEPUTUSAN PEMBELIAN MOBIL AVANZA}

\author{
Philip Samoel \& Bintang Sahala Marpaung \\ Program Studi Pemasaran, Institut Bisnis dan Informatika Kesatuan \\ Bogor, Indonesia \\ Email:lemlit@stiekesatuan.ac.id
}

\section{ABSTRACT}

Based on the research, it is concluded that there is one factor that has a positive and significant effect on the purchase decision variable. The factor is the Consumer Involvement Dimension variable (X2). With the acquisition of $t$-count is greater than $t$ table that is equal to 6.012> 1.660. Then through the F test indicates that there is a positive and significant influence on the purchasing decision with the acquisition of a bigger $f$ - count than the $f$ - table of (83.865> 3.783). With $r$ square value equal to $72,4 \%$ which means independent variable of demography characteristic, consumer engagement dimension, and purchasing decision have positive effect, meaning every increase of demographic characteristic variable, dimension of consumer involvement, and purchasing decision one-unit hence variable purchase decision will increased by 3,009 and the rest of $27,6 \%$ influenced by other variable not examined in this research.

Keywords : Demographic Characteristics, Dimensions of Consumer Involvement, Needs Introduction and Purchase Decision.

\title{
PENDAHULUAN
}

Seorang tenaga pemasaran dituntut agar mengetahui detail demografi dan sub budaya dalam menentukan segmentasi pasar produknya. Hal ini sangat membantu tenaga pemasaran dapat mengetahui pasar-pasar yang potensial dan sesuai dengan karakteristik produk yang ditawarkan. Untuk membedakan kelompok-kelompok konsumen, pemasar harus menggunakan variabel-variabel demografi yang merupakan masalah dasar dalam menentukan segmentasi pasarnya.

Dari informasi demografi yang ada dapat mencerminkan gambaran kebutuhan konsumen yang berbeda-beda. Pengenalan kebutuhan merupakan langkah awal dalam proses pengambilan keputusan pembelian, dimana konsumen langkah ini membantu konsumen dalam mengenali suatu masalah atau kebutuhannya. Dalam proses pengenalan kebutuhan, pembeli akan menyadari bahwa sesungguhnya terdapat perbedaan antara keadaan nyata (penawaran pasar) dengan keadaan yang diinginkan (kebutuhan atau demand).

Kebutuhan konsumen atas sebuah produk, sangat dipengaruhi oleh kepentingan seseorang yang ditimbulkan oleh adanya rangsangan lingkungan. Sebelum memutuskan untuk membeli sebuah produk, biasanya seorang konsumen terlebih dahulu perlu mengalami keterlibatan atas suatu produk. Sehingga seorang konsumen, dituntut agar lebih pintar dalam mengambil keputusan terutama dalam menentukan produk mana yang akan dibeli diantara produk-produk yang ditawarkan. Begitu pula halnya dengan keputusan konsumen terhadap pembelian barang mewah seperti mobil, dimana kondisi persaingan sangat tinggi, tentu hal ini akan membingungkan konsumen dalam menentukan produk mana yang akan dikonsumsi/dibeli. Kecenderungannya konsumen 
Pengaruh

Karakteristik

Demografi,

Dimensi

Keterlibatan

konsumen, dan

Pengenalan

Kebutuhan

Terhadap

Keputusan

Pembelian

Mobil Avanza

$\underline{278}$ akan melibatkan orang lain untuk membantunya dalam mengambil keputusan untuk membeli produk yang paling sesuai dengan kebutuhannya, dari beberapa pilihan produk yang ditawarkan oleh para produsen.

\section{TINJAUAN PUSTAKA}

\section{Keputusan Pembelian}

Proses pengambilan keputusan yang rumit sering melibatkan beberapa keputusan. Suatu keputusan (decision) melibatkan pilihan diantara dua atau lebih alternatif tindakan (atau perilaku). Keputusan mensyaratkan pilihan diantara beberapa perilaku yang berbeda (Nugroho, 2008).

Menurut Kotler dan Amstrong (2008) bahwa: "Keputusan pembelian adalah tahap proses keputusan dimana konsumen secara actual melakukan pembelian produk".

\section{Karakteristik Demografi}

Menurut Kotler dan Amstrong yang dikutip oleh Etta Mamang Sangadji dan Sophia, (2013), bahwa demografi adalah ilmu tentang populasi manusia dalam hal ukuran, kepadatan, lokasi, umur, jenis kelamin ras, mata pencaharian, pendidikan, pendapatan, agama, dan lainnya.

Lingkungan demografis adalah kepentingan utama bagi pemasar karena lingkungan ini melibatkan orang-orang yang akan membentuk pasar.

\section{Dimensi Keterlibatan Konsumen}

Menurut McKechnie (2012), keterlibatan adalah tingkat kepentingan pribadi yang dirasakan dan/minat yang dibangkitkan oleh stimulus di dalam situasi yang spesifik hingga jangkauan kehadiranya, konsumen bertindak dengan sengaja untuk meminimalkan resiko dan memaksimalkan manfaat yang diperoleh dari pembelian dan pemakaian.

Keterlibatan konsumen adalah pribadi yang dirasakan penting dan/atau minat konsumen terhadap perolehan, konsumsi, dan disposisi barang, jasa atau ide. Keterlibatan konsumen adalah tindakan proaktif yang dilakukan konsumen terhadap stimulus yang diberikan pemasar/produsen yang ditunjukan untuk meminimalkan risiko dan memaksimalkan keuntungan atau manfaat atas pembelian produk, sesuai dengan pendapat Jones (2008).

\section{Pengenalan Kebutuhan}

Menurut Engel, Blackwell, dan Miniard, yang dikutip oleh Ujang Sumarwan (2011) pengenalan kebutuhan muncul ketika konsumen menghadapi masalah, yaitu suatu keadaan dimana terdapat perbedaan yang sebenarnya terjadi.

\section{METODE PENELITIAN}

Metode yang digunakan dalam penelitian ini adalah metode pendekatan kuantitatif, yaitu teknik analisis data yang berkenaan dengan perhitungan untuk menjawab rumusan masalah dan pengujian hipotesis, dengan menggunakan kuesioner sebagai alat analisis 
dalam mencari tanggapan responden mengenai karakteristik demografi, dimensi keterlibatan konsumen, pengenalan kebutuhan dan keputusan pembelian.

Selanjutnya data yang diperoleh melalui penyebaran kuisioner, diolah dan akan disajikan dalam bentuk tabel. Hasil olah data kemudian dianalisis yaitu : variabel Karakteristik Demografi, Dimensi Keterlibatan Konsumen, dan Pengenalan Kebutuhan. Berdasarkan hasil olah data, dapat dilihat pengaruhnya terhadap keputusan pembelian mobil avanza. Selanjutnya akan dilakukan uji analisis regresi linear berganda, sehingga dapat diketahui hubungan yang terjadi antara dua variabel yaitu variabel independent dan variabel dependent.

\section{HASIL DAN PEMBAHASAN}

Pengaruh Karakteristik Demografi, Dimensi Keterlibatan Konsumen, dan Pengenalan Kebutuhan Terhadap Keputusan Pembelian Mobil Avanza

\section{Koefisien Korelasi dan Koefisien Determinasi}

Koefisien determinasi dimaksudkan untuk mengetahui seberapa besar pengaruh variable dependent. Berikut hasil pengolahan data yang sudah dilakukan:

Tabel 1

Model Summary

\begin{tabular}{lcccc} 
Model & $R$ & R Square & $\begin{array}{c}\text { Adjusted } R \\
\text { Square }\end{array}$ & $\begin{array}{c}\text { Std. Error of } \\
\text { the Estimate }\end{array}$ \\
\hline 1 & $.851^{\mathrm{a}}$ & .724 & .715 & 1,945 \\
\hline
\end{tabular}

a. Predictors: (Constant), Pengenalan Kebutuhan,

Karakteristik Demografi, Dimensi Keterlibatan

Konsumen.

Berdasakan tabel diatas, diperoleh $\mathrm{r}$ atau koefisien korelasi sebesar 0,851 sehingga dapat diketahui bahwa ada hubungan yang kuat antara variabel independen (karakteristik demografi, dimensi keterlibatan konsumen, pengenalan kebutuhan. dengan variabel dependen yaitu : keputusan pembelian).

Berdasarkan hasil perhitungan diperoleh nilai $\mathrm{R}^{2}$ atau koefisien determinasi sebesar 0,724 atau $72,4 \%$, artinya variabel tersebut memiliki pengaruh yang sangat kuat. Dengan demikian dapat dikatakan bahwa : variabel independen yang terdiri dari kerakteristik demografi $\left(\mathrm{X}_{1}\right)$, dimensi keterlibatan konsumen $\left(\mathrm{X}_{2}\right)$, pengenalan kebutuhan $\left(\mathrm{X}_{3}\right)$, mampu menjelaskan keragaman atau variabilitas dari variabel keputusan pembelian (Y) sebesar $72,4 \%$, sedang sisanya sebesar $27,6 \%$ dipengaruhi oleh variabel lain yang tidak diteliti dalam model penelitian ini.

\section{Pembentukan Persamaan Regresi}

Setelah dilakukan perhitungan, maka diperoleh hasil perhitungan sebagai berikut:

Tabel 2

Pembentukan Persamaan Regresi 


\begin{tabular}{lcccccc}
\hline & \multicolumn{2}{c}{$\begin{array}{c}\text { Unstandardized } \\
\text { Coefficients }\end{array}$} & $\begin{array}{c}\text { Standardized } \\
\text { Coefficients }\end{array}$ & & \\
\cline { 2 - 4 } Model & B & $\begin{array}{c}\text { Std. } \\
\text { Error }\end{array}$ & Beta & T & Sig. \\
\hline 1 & 3,009 & 1,558 & & 1,931 &, 056 \\
\hline $\begin{array}{l}\text { (Constant) } \\
\text { Karakteristik } \\
\text { Demografi }\end{array}$ &, 032 &, 044 &, 040 &, 740 &, 461 \\
\hline $\begin{array}{l}\text { Dimensi } \\
\text { Keterlibatan } \\
\text { Konsumen }\end{array}$ & 1,002 &, 167 & 1,577 & 6,012 &, 000 \\
\hline $\begin{array}{l}\text { Pengenalan } \\
\text { Kebutuhan }\end{array}$ &, 522 &, 181 &, 758 & 2,887 &, 005 \\
\hline
\end{tabular}

Rumus:

$$
\hat{\gamma}=a+b x_{1}+c x_{2}+d x_{3}+\text { error }
$$

$\hat{\gamma}=3,009+0,032 x_{1}+1,002 x_{2}+0,522 x_{3}+$ error

Berdasarkan persamaan regresi, maka diperoleh :

a. Jika $\mathrm{X}_{1}=\mathrm{X}_{2}=\mathrm{X}_{3}=\varnothing$ maka $\hat{\gamma}$ (Keputusan Pembelian) $=3,009$

b. Jika $X_{1}$ (Karakteristik Demografi) naik sebesar 1 (satu) satuan maka Y (Keputusan Pembelian) akan naik sebesar 0,032 jika variabel lain dianggap konstan.

c. Jika $\mathrm{X}_{2}$ (Dimensi Keterlibatan Konsumen) naik sebesar 1 (satu) satuan maka Y (Keputusan Pembelian) akan naik sebesar 1,002 jika variabel lain dianggap konstan.

d. Jika $\mathrm{X}_{3}$ (Pengenalan Kebutuhan) naik sebesar 1 (satu) satuan maka Y (Keputusan Pembelian) akan naik sebesar 0,522 jika variabel lain dianggap konstan.

\section{Uji Hipotesis}

\section{Uji Simultan (Uji F)}

Pengujian ini dilakukan untuk melihat ada atau tidaknya hubungan antara variabel $\mathrm{X}$ (karakteristik demografi, dimensi keterlibatan konsumen, dan pengenalan kebutuhan) terhadap variabel Y (keputusan pembelian) secara simultan 


\begin{tabular}{|c|c|c|c|c|c|c|}
\hline Model & & $\begin{array}{c}\text { Sum of } \\
\text { Squares }\end{array}$ & Df & Mean Square & $\mathrm{F}$ & Sig. \\
\hline \multirow[t]{3}{*}{1} & Regression & 951,820 & 3 & 317,273 & 83,865 &, $000^{b}$ \\
\hline & Residual & 363,180 & 96 & 3,783 & & \\
\hline & Total & 1315,000 & 99 & & & \\
\hline
\end{tabular}

a. Dependent Variable: Y

b. Predictors: (Constant), Pengenalan Kebutuhan, Karakteristik Demografi, Dimensi Keterlibatan Konsumen

Tabel diatas, menunjukkan hubungan antara karakteristik demografi, dimensi keterlibatan konsumen, dan pengenalan kebutuhan terhadap keputusan pembelian, yaitu : dengan $\alpha=5 \%, \mathrm{df}_{1}=3, \mathrm{df}_{2}=96$.

Hubungan antara variabel X (karakteristik demografi, dimensi keterlibatan konsumen, dan pengenalan kebutuhan, dengan variabel Y (keputusan pembelian), adalah sebagai berikut :

$\mathrm{H}_{0}: \beta=0$ Tidak terdapat pengaruh antara karakteristik demografi, dimensi keterlibatan konsumen, dan pengenalan kebutuhan, dengan keputusan pembelian

$\mathrm{H}_{1}: \beta \neq 0$ Terdapat pengaruh antara karakteristik demografi, dimensi keterlibatan konsumen, dan pengenalan kebutuhan, dengan keputusan pembelian.

Berdasarkan tabel diatas, diperoleh nilai $\mathrm{F}$ hitung sebesar 83,865 dan $\mathrm{F}$ tabel sebesar 3,783, dengan demikian maka $\mathrm{F}$ hitung lebih besar dari $\mathrm{F}$ tabel atau $(83,865>$ 3,783). Dapat dikatakan bahwa hipotesis pertama diterima, $\mathrm{H}_{0}$ ditolak dan $\mathrm{H}_{1}$ diterima, artinya ada hubungan yang signifikan antara karakteristik demografi, dimensi keterlibatan konsumen, dan pengenalan kebutuhan dengan keputusan pembelian.

\section{Uji Parsial (Uji t)}

Pengujian ini dilakukan untuk melihat ada atau tidaknya hubungan antara variabel-variabel $\mathrm{X}$ (karakteristik demografi, dimensi keterlibatan konsumen, dan pengenalan kebutuhan, terhadap variabel Y (keputusan pemebelian) secara terpisah.

\section{Hipotesis 1 Karakteristik Demografi terhadap Keputusan Pembelian}

Hipotesis dibuat sebagai berikut:

$\mathrm{H}_{0}: \beta=0$ Tidak terdapat pengaruh antara Karakteristik Demografi dengan Keputusan Pembelian

$\mathrm{H}_{1}: \beta \neq 0$ Terdapat pengaruh antara Karakteristik Demografi dengan Keputusan Pembelian

Berdasarkan hasil perhitungan diperoleh nilai t hitung sebesar 0.740 dan $\mathrm{t}$ tabel sebesar 1,660 dengan demikian maka t hitung lebih besar dari t tabel atau $(0.740<1,660)$. Dengan demikian hipotesis satu diterima, $\mathrm{H}_{0}$ diterima dan $\mathrm{H}_{1}$ ditolak, artinya tidak ada hubungan yang positif dan signifikan antara karakteristik demografi dengan keputusan pembelian.

Hipotesis 2 Pengaruh Antara Dimensi Keterlibatan Konsumen terhadap Keputusan Pembelian 
Hipotesis dibuat sebagai berikut:

$\mathrm{H}_{0}: \beta=0$ Tidak terdapat pengaruh antara Dimensi Keterlibatan Konsumen dengan Keputusan Pembeliam

$\mathrm{H}_{1}: \beta \neq 0$ Terdapat pengaruh antara Dimensi Keterlibatan Konsumen terhadap Keputusan Pembelian

Berdasarkan tabel di atas diperoleh nilai t hitung sebesar 6.012 dan t tabel sebesar 1,660 dengan demikian maka thitung lebih kecil dari t tabel atau (6.012 > 1,660). Dengan demikian hipotesis dua diterima, $\mathrm{H}_{0}$ ditolak dan $\mathrm{H}_{1}$ diterima, artinya ada hubungan yang positif dan signifikan antara Dimensi Keterlibatan Konsumen dengan Keputusan Pembelian.

\section{Hipotesis 3 Pengaruh Antara Pengenalan Kebutuhan terhadap Keputusan Pembelian}

Hipotesis dibuat sebagai berikut:

$\mathrm{H}_{0}: \beta=0$ Tidak terdapat pengaruh antara Pengenalan Kebutuhan dengan Keputusan Pembelian

$\mathrm{H}_{1}: \beta \neq 0$ Terdapat pengaruh antara Pengenalan Kebutuhan terhadap Keputusan Pembelian

Berdasarkan hasil perhitungan diperoleh nilai $\mathrm{t}$ hitung sebesar 2.887 dan $\mathrm{t}$ tabel sebesar 1,660, dapat dikatakan bahwa t hitung lebih besar dari t tabel atau $(2.887>1,660)$.

Dengan demikian hipotesis tiga diterima, $\mathrm{H}_{0}$ ditolak dan $\mathrm{H}_{1}$ diterima, artinya ada hubungan yang positif dan signifikan antara pengenalan kebutuhan dengan keputusan pembelian.

\section{PEMBAHASAN}

Berdasarkan hasil perhitungan yang ada, maka dapat dibuat analisis terhadap hipotesis penelitian yang ada, sebagai berikut:

1. Hubungan antara Karakteristik Demografi terhadap Keputusan Pembelian.

Hipotesis 1: Karakteristik Demografi tidak berpengaruh secara positif dan signifikan terhadap Keputusan Pembelian.

Berdasarkan hasil analisis yang telah dilakukan, diperoleh hasil yang menunjukkan bahwa karakteristik demografi tidak berpengaruh secara positif dan signifikan terhadap keputusan pembelian. Dengan besaran pengaruh beta pada variabel karakteristik demografi sebesar 0.032, yang artinya setiap kenaikan variabel karakteristik demografi satu-satuan, maka variabel keputusan pembelian akan naik sebesar 0,032 jika variabel lain dianggap konstan.

2 Hubungan antara Dimensi Keterlibatan Konsumen terhadap Keputusan Pembelian

Hipotesis 2: Dimensi Keterlibatan Konsumen berpengaruh secara positif dan signifikan terhadap Keputusan Pembelian.

Berdasarkan hasil analisis yang telah dilakukan, diperoleh hasil yang menunjukkan bahwa Keterlibatan Konsumen berpengaruh secara positif dan signifikan terhadap Keputusan Pembelian.

Dengan besaran pengaruh beta pada variabel keterlibatan konsumen sebesar 1.002 yang artinya setiap kenaikan variabel keterlibatan konsumen satu-satuan, maka variabel keputusan pembelian akan naik sebesar 1.002 jika variabel lain dianggap konstan. 
3. Hubungan antara Pengenalan Kebutuhan terhadap Keputusan Pembelian

Hipotesis 3: Pengenalan Kebutuhan tidak berpengaruh secara positif dan signifikan terhadap Keputusan Pembelian.

Berdasarkan hasil analisis yang telah dilakukan, diperoleh hasil yang menunjukkan bahwa Pengenalan Kebutuhan tidak berpengaruh secara positif dan signifikan terhadap Keputusan Pembelian.

Dengan besaran pengaruh beta pada variabel Pengenalan Kebutuhan sebesar 0.522 yang artinya setiap kenaikan variabel pengenalan kebutuhan satu-satuan, maka variabel keputusan pembelian akan naik sebesar 0.522 jika variabel lain dianggap konstan.

4. Hubungan antara Karakteristik Demografi, Dimensi Keterlibatan, dan Pengenalan Kebutuhan, terhadap Keputusan Pembelian.

Hipotesis 4 : Karakteristik Demografi, Dimensi Keterlibatan, dan Pengenalan Kebutuhan, terhadap Keputusan Pembelian.

Nilai $\mathrm{r}$ square sebesar $72,4 \%$ yang artinya variable independent (karakteristik demografi, dimensi keterlibatan konsumen, dan keputusan pembelian) berpengaruh secara positif.

\section{SIMPULAN}

Berdasarkan hasil penelitian dan pembahasan yang ada, maka dapat disimpulkan sebagai berikut :

1. Variabel karakteristik demografi tidak berpengaruh secara positif dan signifikan terhadap variabel keputusan pembelian. Artinya saat memutuskan membeli kendaraan bermotor untuk jenis Toyota Avanza, akan terdapat banyak hal yang akan dipertimbangkan, salah satunya adalah karakteristik demografi seperti jenis kelamin, pekerjaan, pendapatan, pengeluaran, status pernikahan, status pendidikan terakhir, tempat tinggal, jumlah anak dan lain-lain. Dengan demikian pihak Toyota dalam memproduksi mobil Avanza hendaknya disesuaikan dengan demografi sehingga masyarakat dapat mempertimbangkan terlebih dahulu sebelum membeli kendaraan tersebut, mengingat harga kendaraan yang akan dibeli bukanlah merupakan barang yang murah harganya.

2. Variabel dimensi keterlibatan konsumen berpengaruh secara positif dan signifikan terhadap variabel keputusan pembelian. Artinya saat akan membeli suatu barang perlu adanya keterlibatan konsumen sebelum membeli, seperti mencari tahu informasi tentang produk yang akan dibeli. Dalam penelitian ini yang dimaksudkan adalah keputusan pembelian terhadap kendaraan Toyota Avanza, dimulai dari mencari informasi mengenai spesifikasi, harga, tampilan dan spesifikasi kendaraan yang akan dibeli.

3. Variabel pengenalan kebutuhan tidak berpengaruh. Artinya tidak adanya pengaruh pada saat membeli atau memutuskan suatu pembelian kendaraan dengan pengenalan akan kebutuhan kendaraan Toyota Avanza.

4. Terdapat pengaruh yang positif antara variabel karakteristik demografi, dimensi keterlibatan konsumen, pengenalan kebutuhan dan keputusan pembelian. Artinya variable independent : karakteristik demografi, dimensi keterlibatan konsumen, dan keputusan pembelian berpengaruh secara positif. Dengan demikian setiap kenaikan

batan

ten, dan

alan 
variabel karakteristik demografi, dimensi keterlibatan konsumen, dan keputusan pembelian satu-satuan maka variable keputusan pembelian akan naik.

\section{DAFTAR PUSTAKA}

Nugroho J. Setiadi. 2008. Perilaku Konsumen : Konsep dan Impilikasi Untuk Strategi dan Penelitian Pemasaran. Jakarta : Kencana.

Kotler, Philip; Armstrong, Garry, 2008. Prinsip-prinsip Pemasaran,Jilid 1, Erlangga, Jakarta.

Mamang Etta Sangadji, Sophia. 2013. Prilaku Konsumen.Yogyakarta : Penerbit Andi.

McKechnie, Sally. (2012). Consumer Buying Behavior in Financial Services : An Overview. North Carolina: University of North Carolina.

Sumarwan, Ujang, Perilaku Konsumen : Teori dan Penerapannya Dalam Pemasaran, Penerbit Ghalia Indonesia, Bogor, 2011 